\title{
TRAMITAÇÃO E DESDOBRAMENTOS DA LDB/1996: EMBATES ENTRE PROJETOS ANTAGÔNICOS DE SOCIEDADE E DE EDUCAÇÃO
}

\author{
PROCEDURING AND UNFOLDING OF LDB/1996: CLASHES AMONG OPPOSING SOCIETAL \\ AND EDUCATIONAL PROJECTS
}

Iria Brzezinski ${ }^{1}$

Resumo Objetiva-se neste artigo analisar a luta no campo das políticas educacionais durante a tramitação da Lei de Diretrizes e Bases da Educação Nacional (lei n. ${ }^{\circ}$ 9.394/1996) no Congresso Nacional e as mudanças mais significativas em seus dispositivos na década pós-lei. Tratam-se dos embates entre os atores de dois mundos com ideários conflitantes sobre as concepções de sociedade, cidadania, educação, escola e ensino: o mundo real, dos educadores, e o oficial, o mundo do sistema educativo. Resultou desses embates, na Câmara dos Deputados, a 'conciliação aberta' entre interesses dos partidários do ensino público e gratuito e do ensino privado como estratégia de inclusão de suas reivindicações no diploma legal. No Senado da República, um balanço dos procedimentos regimentais casuísticos leva à conclusão de que a forte pressão do poder do mundo do sistema (o Executivo), representado pelo Ministério da Educação, favoreceu ações dos interessados no ensino privado, prevalecendo hegemonicamente esses interesses sobre as reivindicações dos defensores do ensino público, laico, gratuito em todos os níveis e de qualidade para todos os cidadãos brasileiros. Nos desdobramentos da lei durante a década posterior, tais procedimentos se replicam, uma vez que permanecem em disputa na arena política dois projetos de educação.

Palavras-chave políticas educacionais; tramitação da LDB/1996; mudanças na lei.
Abstract The purpose of this article is to examine the struggle in the field of educational policies during the proceduring of the Law of Directives and Bases of National Education (Law n. ${ }^{\circ}$ 9394/1996) in Congress and the most significant changes made to its provisions in the decade after the law was enacted. These are the conflicts among the players of two worlds with conflicting ideologies about the conceptions regarding the society, citizenship, education, school and education: the real world, of the educators, and the official one, the educational system universe. These clashes, at the House of Representatives, led to the 'open reconciliation' of the interests of the supporters of free public education and the backers of private schools as a strategy for the inclusion of their demands under the legislation. At the Senate, a review of the casuistic regimental procedures led to the conclusion that the strong pressure exerted by the system's world power (the Executive), represented by the Ministry of Education, favored the actions of private education interests, which prevailed in a hegemonic manner over those of the advocates of public, secular, free, and quality education at all levels for all citizens. Such procedures replicate in the development of the law during the following decade, since the two educational projects remain in contention in the political arena. Keywords educational policies; proceduring of LDB/1996; changes in the law. 
Quem verdadeiramente vive não pode deixar de ser cidadão, e partidário (...) Mais uma vez, não. Sou militante, estou vivo, sinto nas consciências viris dos que estão comigo pulsar a atividade da cidade futura,

que estamos a construir (...) Vivo, sou militante

(Gramsci, 1917).

\section{Notas introdutórias}

Busco em Antonio Gramsci, mencionado em epígrafe, sustentação teórica para afirmar que as tramas legislativas e os embates entre dois projetos de sociedade e de educação foram e ainda são enredados por atores que se localizam em dois mundos cujo ideário é antagônico: o mundo vivido dos educadores e o mundo oficial. Esse antagonismo se manteve acirrado durante a tramitação dos anteprojetos da Lei de Diretrizes e Bases da Educação Nacional (LDB, 20/12/1996), que levou oito anos no Congresso Nacional. Apesar de a LDB ter sido sancionada e implementada com vigor, pelos governos Fernando Henrique Cardoso (1995-2002) e Luiz Inácio Lula da Silva (2003-2006 e 20072009, do segundo mandato), no contexto atual das políticas acirraram-se a disputa e a contradição entre esses mundos. Ambos, o mundo real e o mundo oficial, têm representantes que se mantêm vivos, tomam partido, defendem princípios e propostas, resguardam convicções, alinhados a ideários distintos construídos ao longo da história de cada um.

Sustento-me também na assertiva de que as políticas educacionais brasileiras que se materializaram no LDB/1996 não foram definidas exclusivamente pela burocracia do Poder Executivo, nominado aqui Ministério da Educação (MEC), que se consagrou vencedor por uma 'manobra regimental' nos momentos de votação do Substitutivo de LDB apresentado pelo senador Darcy Ribeiro no âmbito do Poder Legislativo, no Senado da República.

O Fórum Nacional em Defesa da Educação Pública na LDB (Fórum), legítimo representante do mundo real, por intermédio de entidades da sociedade civil que o compunham, também logrou êxito em um ou outro dispositivo da lei, porque acompanhou pari passu as tramas legislativas no Congresso Nacional e participou dos debates e embates entre os dois mundos que se confrontavam tanto no campo das ideias como no das práticas.

Atento às negociações que se faziam nos bastidores do Congresso entre os parlamentares, o Fórum, estrategicamente, conquistava espaço para apresentar as suas propostas aos legisladores simpatizantes com a causa da educação pública e fazia valer seus interesses em defesa desta educação, gratuita, laica e de qualidade socialmente referenciada para todos os brasileiros, em todos os níveis e modalidades de formação. É preciso revelar também que foram 
muitas as investidas das entidades reunidas no Fórum contra parlamentares que se associavam ao mundo oficial e buscavam, em sintonia com os princípios neoliberais, defender interesses do sistema particular de ensino. Mesmo que não atendido em suas reivindicações por esse grupo de parlamentares que defendiam o ensino privado, o Fórum participava das audiências com esses parlamentares para, pelo menos, se fazer ouvir e mostrar resistência aos encaminhamentos contrários à escola pública, direito de todo cidadão brasileiro.

Cabe nestas notas introdutórias explicitar que o caminho a ser percorrido para elaborar o presente artigo é traçado nas trilhas do contraditório entre os já citados dois mundos e do antagonismo de seus ideários e projetos conflitantes. Essa minha assunção não é novidade, pois a renovo com frequência na sistematização de minhas pesquisas e trabalhos científicos à medida que faço uso de uma análise histórica e política da sociedade, da educação e da cultura inspirada nos ensinamentos de Anísio Teixeira (1962). Esta análise pressupõe no jogo das interações contemporâneas a existência de dois mundos bem definidos: um mundo do sistema - o oficial e, outro, o mundo real - o mundo vivido. Este mundo real na sociedade brasileira, sob minha perspectiva, é aquele construído na luta dos educadores, travada desde os anos 1980, para resistir e tentar modificar as práticas autoritárias de traçar políticas educacionais consentâneas com interesses apenas dos que detêm o poder econômico e político em nosso país. Destaco ainda que o mundo vivido tem como prática a defesa da cidadania e que se coloca, dialeticamente, como um movimento mais vigoroso a cada vez que aparenta ter sido desmobilizado pelos golpes desferidos pelo mundo oficial. Este, por sua vez, é considerado por mim como aquele em que, com aporte nos princípios, políticas e práticas neoliberais, vem saudando a globalização excludente como sinal inquestionável de desenvolvimento sustentável, de modernidade, de qualidade de vida no planeta, reafirmando a parceria com elites dominadoras e com o capital estrangeiro que ditam normas para as políticas públicas brasileiras determinadas pelo Estado Mínimo Nacional.

Como existe um acentuado distanciamento entre esses dois mundos, existe também um forte distanciamento entre a letra da lei n. ${ }^{\circ}$ 9.394/1996 e o real reve-lado nos sistemas educacionais federal, estadual e municipal e, particularmente, mostrado pela ponta do sistema educacional brasileiro: a escola da Educação Básica e as instituições da Educação Superior.

\section{Tramas legislativas e embates na disputa entre o ideário do mundo vivido e o do mundo oficial}

Recupero de modo bastante sucinto, diante dos limites impostos pela natureza deste ensaio, algumas 'fatias' da História da Educação Brasileira para 
demonstrar que os antagonismos entre o ideário dos dois mundos encontra suas raízes no longo período de 13 anos² de tramitação no Congresso Nacional da primeira LDB, lei n. ${ }^{\circ} 4.024$, de 20/12/1961.

Refiro-me a algumas 'fatias' da história porque concordo com Veyne (1982, p. 17) que “o campo da história é, pois, inteiramente indeterminado, com uma única exceção: é preciso que tudo o que nele se inclua tenha, realmente, acontecido". Diante desta prerrogativa da indeterminação do campo, o historiador "seleciona, simplifica, organiza, faz com que um século caiba numa página" (Veyne, 1982, p. 11), porém o ethos de sua narrativa encontra-se em incluir sempre o acontecido de modo a revelar a historicidade dos fatos, vinculando-os às condições concretas que os acompanham, contextualizando-os. Caso contrário, o narrador fará romance ou ficção. Com efeito, tenderá a revelar a 'não' História.

Como dito, uma 'fatia' da história da existência de dois mundos na tramitação da lei n. ${ }^{\circ}$ 4.024/1961 é narrada pela trajetória do projeto dessa Lei de Diretrizes e Bases da Educação Nacional (LDBEN) no Congresso Nacional. Em 1948, foi iniciada sua tramitação, passaram-se, contudo, dez anos para que o debate se acirrasse, motivado pelo Substitutivo de Carlos Lacerda apresentado à Câmara dos Deputados.

Saviani (1997, p. 12) salienta que o Substitutivo Lacerda mudou os rumos do projeto original que tinha como eixo a organização de um sistema nacional de educação e a descentralização, "esposada desde a década de 30 pela Associação Brasileira de Educação (ABE)". A meu ver, à época, essa associação foi representante do mundo vivido, porque defendia a democratização dos saberes, a descentralização do ensino, a escola básica e a universidade pública como direito do cidadão brasileiro, princípios expressos no Manifesto dos Pioneiros da Escola Nova (1932).

As mudanças propostas por Carlos Lacerda afrontavam os princípios dos Pioneiros da Escola Nova, visto que o parlamentar incorporou ao seu substitutivo as conclusões do III Congresso Nacional de Estabelecimentos Particulares de Ensino. Segundo Saviani (1997, p. 15), este fato conduziu "os representantes dos interesses das escolas particulares" a tomarem a "dianteira do processo" de tramitação da primeira LDB. Reconheço Carlos Lacerda como representante de um mundo de interesses dos 'católicos' privatistas que desejavam preservar as oportunidades educacionais para as classes dominadoras, para as elites. Interesses semelhantes aos preservados pelo mundo oficial, uma vez que desde os primórdios da organização do sistema educacional brasileiro até os dias atuais, o sistema centra-se em um modelo dualista de modo que convivam nele escolas públicas e privadas, escolas para ricos e escola para pobres.

Reside nas divergências mencionadas a divisão dos educadores entre dois mundos em conflito: um deles era formado pelos educadores profissionais, 
os liberais (social-democratas), e os outros, pelos intelectuais católicos unidos à hierarquia da Igreja Católica. Essa elite intelectual de católicos leigos tinha como missão, entre outras, enfrentar a ameaça dos liberais, supostamente comunistas, bem como restaurar a aproximação da Igreja Católica com o Estado, rompida com o advento do regime republicano em 1889. Neste sentido, a colaboração dos intelectuais católicos para o Brasil procurava conquistar, junto aos governantes, o reconhecimento oficial ou semioficial da Igreja Católica. Exemplo disto, na década de 1930, foi a inserção do ensino religioso nos currículos da Educação Básica por Francisco Campos, ministro da Educação, simpatizante do grupo católico, como bem explicita Saviani (2007).

A análise que venho empreendendo neste artigo permite-me localizar, de um lado, o mundo vivido liderado pelos educadores profissionais afiliados à tendência educacional da Escola Nova ancorada nas matrizes do ideário liberal que defendia o Estado laico e democrático, visando à reconstituição da Nação Republicana por meio da educação e pleiteava a instalação da escola básica única e gratuita para todos os brasileiros. De outro lado, localizo o mundo 'oficial' formado pelos intelectuais católicos, que pretendiam recristianizar a nação, mantendo o ideário da Pedagogia Tradicional, conservadora, acrítica, como pilar de suas ações discriminadoras e não emancipatórias, pois a escola básica, segundo esses católicos leigos deveria servir aos filhos das classes privilegiadas. Ao dar destaque ao anacronismo e ao caráter excludente da escola ideológica de "fundo conservador" para classes dominantes, Cury (1994, p. 19) critica a ideologia da Igreja Católica, sólida instituição, que "se posicionava claramente a favor do ensino acadêmico, classicista e sobretudo classista".

É preciso explicar porque localizo os intelectuais católicos leigos como mundo 'oficial'. Ainda que tais atores não se abrigassem sob a proteção explícita do poder da sociedade política e não representassem o poder estatal, a Igreja Católica mantinha forte influência na política educacional como aparelho ideológico do Estado. É evidente a vinculação oficial, desde a Constituição de 1824, entre a "presença da Igreja nas instituições de beneficência e educação" (Cury, 1984, p. 13) e a manutenção das atividades 'beneficientes' e 'filantrópicas' pelo Estado, em face de que nesse dispositivo legal o Império Brasileiro se proclamou constitucionalmente católico, o que tornou oficial o que ocorria desde o período colonial.

Cury (1984) fez um detalhado estudo das divergências entre católicos e liberais no contexto dos anos 1930 e, particularmente, revelou os antagonismos ideológicos entre esses dois grupos no processo de elaboração da Constituição Brasileira de 1934. Tais antagonismos e conflitos, todavia, replicaram-se em 1947-1948, durante a elaboração do projeto da lei 4.024/1961 e sua tramitação no Congresso Nacional. Ocasião em que os católicos se organizaram, mais uma vez, a favor do ensino privado e os liberais defendiam o ensino 
público. Sendo assim, sinto-me sustentada em aportes teóricos de Cury (1984) para identificar os intelectuais católicos e a hierarquia da Igreja como participantes do mundo 'oficial', pois seus ideais e princípios penetraram as políticas educacionais prescritas na primeira LDBEN/1961.

No período de tramitação do projeto de LDB atual (1988-1996), o conflito público versus privado, a disputa entre dois projetos de sociedade e de educação voltam ao cenário político-ideológico, porém marcaram presença novos atores. Um fenômeno contribuiu para isto: as escolas básicas confessionais católicas e algumas escolas públicas foram paulatinamente retirando-se do cenário educacional, para dar lugar às escolas privadas laicas em decorrência das profundas transformações da sociedade brasileira e das relações de produção que passaram a favorecer a versão perversa do capitalismo globalizado, neoliberal, cujo maior regulador é o mercado. Muitos aspectos então impulsionaram uma nova força hegemônica no campo educacional, com nítida tendência de conceber as instituições educacionais tanto da Educação Básica quanto da Educação Superior como empresas de ensino, e estas mobilizaram um grupo de atores sociais configurado pelos proprietários de escolas particulares e seus lobistas que se pautam exclusivamente pela lógica do lucro.

A este respeito Florestan Fernandes se manifestou alegando que da nova reconfiguração da sociedade, da economia, da política e da educação brasileiras no período de redemocratização do país, nos anos 1980-1990, decorreu

(...) um fortalecimento generalizado e energético do privatismo escolar e do 'neoliberalismo' econômico, como propulsores da articulação de diversos tipos de empresa. As probabilidades de êxito são relativas. Mas é necessário avaliá-las à luz das agências de financiamento internacional e norte-americanas, que pretendem incrementar rapidamente a privatização e destruir um sistema de instituições públicas que opõem o Estado e a Nação à dominação imperialista e à internacionalização dos nossos recursos materiais e humanos (Fernandes, 1990, p. 143).

Foi assim, neste contexto da globalização de todos os setores da vida social, que as classes dominantes e responsáveis pela gestão econômica e política do país, aliadas aos parceiros estrangeiros, induziram o Brasil à inserção na ordem mundializada de modelo neoliberal.

O cenário da tramitação da LDB/1996 revelou o campo de disputa ideológica entre o público e o privado, tendo como foco a relação conflitante entre a defesa da escola pública, laica, gratuita para todos e de qualidade socialmente referenciada em todos os níveis de escolarização, e o ensino privado, administrado pelos empresários que não encontraram obstáculos da sociedade política para transformar em mercadoria o direito à educação preceituado na Constituição de 1988. 
Esse cenário foi marcado no Congresso Nacional por uma disputa na arena de poder na qual se aglutinaram forças de alguns parlamentares do Colégio de Líderes em torno das reivindicações do mundo vivido dos educadores, representado pelo Fórum, bem como de outros parlamentares que atendiam interesses dos empresários e lobistas do ensino privado.

As disputas instigaram o uso de diferentes estratégias pelos líderes partidários em sessões na Câmara dos Deputados. Momentos de muita tensão entre princípios, concepções de sociedade, de cidadania, de educação, de escola e de ensino eram superados somente por meio de acordos partidários, construídos em um processo de longas interlocuções entre os líderes que encontravam certo equacionamento por meio de conciliações.

Interessante análise é realizada por Didonet (2008) sobre o papel exercido por dois líderes partidários na Câmara dos Deputados que simpatizavam com a causa do Fórum: Florestan Fernandes e Ubiratan Aguiar. Para o autor, ambos transcenderam a condição de simples elaboradores de pareceres técnicos e substitutivos ao anteprojeto de LDB ao se revelarem "verdadeiros promotores e coordenadores de debates, estimuladores de manifestações de opiniões" (Didonet, 2008, p. 42), que retratassem um consenso do mínimo necessário em consonância às diretrizes educacionais prescritas na Constituição Federal (1988).

Como as próprias palavras indicam - conciliação e consenso -, implicam perdas para ambos os lados envolvidos em negociação. No entanto, ponderava o deputado Florestan Fernandes que as questões polêmicas eram negociadas com diálogos acirrados e abertos. Essas situações permitiram ao deputado assinalar que o anteprojeto de lei conseguiu ser aprovado, após algumas versões negociadas, porque resultante de uma ampla 'conciliação aberta' no Colégio de Líderes: trata-se do anteprojeto de lei n. ${ }^{\circ} 1.258-\mathrm{C}^{3}$ aprovado pelo plenário dos deputados federais, em 13/05/1993. Esse anteprojeto, conhecido também como Substitutivo Ângela Amim, foi reconhecido como legítimo instrumento definidor de políticas educacionais construído pelo legislativo federal. Tal fato contradizia as ocorrências das formulações dos diplomas relativos ao campo da educação como procedimentos tradicionalmente oriundos do Poder Executivo, desvelando agora certa tendência para o exercício democrático equilibrado entre os poderes constitutivos da República.

Nesta ocasião, a euforia tomou conta dos membros constituintes do Fórum, depois da vivência de tantas situações angustiantes frente ao sentimento de perdas a cada vitória alcançada pelos defensores da escola privada durante cinco anos de tramitação na Câmara. Embora o anteprojeto aprovado não correspondesse à maioria dos interesses dos adeptos da escola pública, gratuita, laica e de qualidade em todos os níveis, para todos os brasileiros, a data da aprovação passou a ser otimisticamente aceita como o dia 
da libertação da LDB, por analogia à libertação dos escravos no Brasil, ocorrida em 13/05/1888.

Como anteriormente citado, foram muitas as perdas referentes às reivindicações do Fórum, mas destaco uma das mais significativas. Foi considerada inconstitucional pela Comissão de Constituição, Justiça e Cidadania (CCJC) a matéria contida em um artigo que estabelecia a criação de um Fórum Nacional, integrado por representantes de educadores da sociedade civil, que teria a atribuição de propor políticas educacionais à sociedade política, neste caso o MEC e seus órgãos, entre eles o Conselho Nacional da Educação.

Na sequência da tramitação do anteprojeto, outros caminhos foram inaugurados no Senado Federal, regimentalmente instituído como 'casa' revisora. Por meio de artimanhas de bastidores nesta instância do Parlamento, o Poder Executivo representado pelo Ministro da Educação exercitou seu poder de barganha e de 'troca de favores', conseguindo assim a adesão de senadores para defender casuisticamente a entrada nessa 'casa' de um novo anteprojeto de lei n. ${ }^{\circ}$ 67/1992, de autoria do senador Darcy Ribeiro. Tal ato anulou a condição do Senado de 'casa' revisora, transformando-o em 'casa' receptora para o assunto LDB.

O anteprojeto de LDB da Câmara dos Deputados recebeu o número PLC n. ${ }^{\circ}$ 101/1993 no Senado e seu relator na Comissão de Educação foi Cid Sabóia, porém, como dito, por imposição regimental, o anteprojeto de lei de Darcy Ribeiro transformou-se em referência para o relator elaborar seu substitutivo e não o anteprojeto (Substitutivo Ângela Amin) encaminhado pela Câmara.

Destaco, contudo, que o senador Cid Sabóia preservou as particularidades da construção do anteprojeto da Câmara, dando voz aos interlocutores representantes dos partidos políticos, do Executivo, das entidades, dos representantes do Fórum, entre outros.

Houve um grande 'enxugamento' do projeto para se transformar em Substitutivo Cid Sabóia, PL n. ${ }^{\circ}$ 250/Senado da República, sendo aprovado na Comissão de Educação e encaminhado ao plenário da nova 'casa propositora', em 12/12/1994.

Não por acaso o Substitutivo Cid Sabóia foi condenado ao arquivamento, pois o Congresso Nacional e o Poder Executivo foram reconstituídos, em decorrência das eleições de 1994. Em face disso, indaga-se: O que ocorreu em fevereiro de 1995? Reinaugurou-se a tramitação do anteprojeto de LDB, após anos de embates, discussões, debates, disputas, tramas, conluios e tramoias legislativas.

Foi evidente o desinteresse do Legislativo neste momento provocado pelas mudanças e os novos políticos no Senado Federal precisavam se inteirar da LDB e de tantos outros anteprojetos herdados da legislatura anterior. Ademais, como é sabido, as questões de políticas educacionais não são matéria prioritária, por isso também o descaso pelo anteprojeto de LDB. O recuo do Legislativo não passou despercebido pelo Executivo (MEC) que, retomando 
a si o papel de tratar das políticas educacionais, passou a dominar o processo e a ter presença ativa no espaço legislativo em relação à LDB. Foi oportunidade também de o novo governo dar visibilidade a outros atores, enquanto que, por diversas razões, pouco a pouco foi sendo retirada a legitimidade do Fórum naquele espaço social de lutas e disputas em favor da escola pública.

Astuciosamente, o próprio autor do anteprojeto do Senado, Darcy Ribeiro, nessa nova etapa de tramitação do projeto foi escolhido relator na Comissão de Constituição, Justiça e Cidadania (CCJC). Investido desta autoridade e de poder a ele conferido, Darcy Ribeiro apontou inúmeras inconstitucionalidades aos dispositivos do anteprojeto da Câmara dos Deputados e ao Substitutivo Cid Sabóia, declarando seu voto pela rejeição de ambos.

Pino (2007) comenta os resultados dessa atitude de Darcy Ribeiro:

a votação imediata do referido parecer na CCJC e sua aprovação em plenário do Senado trariam, como consequência, a eliminação definitiva tanto do projeto da LDB aprovado na Câmara de Deputados, quanto do Substitutivo Cid Sabóia até então em tramitação no Senado (Pino, 2007, p. 40).

Com efeito, as estratégias regimentais favoreceram a aprovação do Substitutivo Darcy Ribeiro pelo plenário do Senado Federal. De imediato foi encaminhado à Câmara dos Deputados, como projeto único e depois sancionado pelo presidente da República em 20/12/1996. Fernando Henrique Cardoso, então presidente, em cadeia radiofônica nacional no programa $A$ voz do Brasil, lançou a ideia de a lei n. ${ }^{\circ} 9.394$ ser cognominada LDB 'Darcy Ribeiro'. Entre os educadores não teve ressonância alguma esse ato de $\mathrm{FHC}$, porque decepcionados com os encaminhamentos dados pelo senador Darcy Ribeiro, que investiu por várias vezes contra as políticas educacionais autoritárias da ditadura militar, mostrando-se defensor da democracia e da educação pública, revela-se, neste episódio, inimigo dos educadores brasileiros, pois se rendeu às artimanhas regimentais provocadas pelo Executivo no âmbito do Legislativo. Enfim, a LDB/1996 transformou-se, autoritariamente, em mais uma lei do Executivo.

Nesta perspectiva, o desafio que me imponho neste instante é, em um exercício de síntese, passar a mencionar no item que segue algumas mudanças ocorridas na lei n. ${ }^{\circ}$ 9.394/1996 no transcorrer de seus dez anos de vigência.

\section{Algumas alterações na LDB/1996 na década da educação}

A tentativa de elaborar uma síntese dos aspectos mais importantes que foram provocando mudanças na LDB/1996, até 2009, exige que detalhes deixem de ser considerados, razão que justifica o termo 'algumas' no título do presente 
item. Na verdade, os dispositivos da LDB/1996 deveriam ser aplicados e seus diversos desdobramentos exigiram múltiplas medidas provisórias, leis, decretos, resoluções, pareceres, e outros.

Não resta dúvida de que no processo de exequibilidade da lei houve concessões dos movimentos sociais organizados na sociedade civil em face da determinação do Estado Mínimo, porém os movimentos de educadores estiveram sempre em alerta na defesa da escola pública, porque adeptos do Estado do Bem-Estar Social. Este requer um outro projeto de sociedade e de educação que se contrapõe ao modelo de educação, de ensino e de escola decorrente do modelo econômico e político estatal brasileiro da contemporaneidade - a globalização neoliberalizante -, como anteriormente explicitado.

A meu ver, para enfrentar o desafio de proceder a um recorte nos desdobramentos da LDB/1996 e a elaboração da síntese aqui proposta, no mínimo, duas questões me instigam. São elas: Ao longo do transcurso de mais de uma década da LDB/1996, foram abrandadas as contradições e as disputas entre o ensino público e o ensino privado?

Foi possível um maior desenvolvimento do campo educacional na Década da Educação?

\section{Recorte e síntese de mudanças mais significativas na LDB}

A partir de 1997, outro cenário se apresenta em relação às políticas educacionais. Esse ano delimita, conforme a lei n. ${ }^{\circ}$ 9.394/1996, o início da Década da Educação. Nesta oportunidade, o Fórum Nacional em Defesa da Educação Pública na LDB abrandou suas ações em relação à lei n. ${ }^{\circ}$ 9.394, pois cumprira com legitimidade acadêmico-profissional e compromisso político a missão de movimento reivindicatório e defensor dos interesses da educação pública durante a tramitação. Em particular, o Fórum historicamente deixou fortes marcas de investidas para a garantia de financiamento do Estado para as políticas sociais, de corte educacional.

Permaneceram no novo cenário pós-1996 os antigos atores sociais, tais como: associações, entidades e sindicatos que integravam o Fórum e mantiveram sua vigilância às políticas educacionais assumidas pelos governos de FHC e Lula. Foram retomadas por essas entidades expressivas manifestações tanto de modo isolado como em conjunto.

Dou realce ao movimento de algumas associações científico-acadêmicas 4 que passaram a reivindicar, produzir documentos, publicar, realizar eventos, participar de oitivas, de audiências públicas e agir conjuntamente na condição de interessados em, entre outros aspectos, no papel do Estado na educação, no dos sistemas educativos, nas transformações estruturais provocadas pela reorganização das instituições educacionais, nas reformas da educação 
básica e superior, na elaboração de diretrizes curriculares para os cursos do ensino superior, na elaboração do Plano Nacional da Educação (PNE/2001), nas inovações educacionais e no uso das tecnologias da informação e comunicação, na criação dos fundos de Manutenção e Desenvolvimento do Ensino Fundamental e de Valorização do Magistério - Fundef/1996 e Fundeb/2007 -, na instalação do Sistema Nacional de Avaliação do Ensino Superior (Sinais).

É lícito afirmar que os diversos desdobramentos da LDB e as mudanças deles decorrentes se realizaram como parte do processo de hegemonia do Estado avaliador e regulador, condição bastante presente nas entrelinhas da lei n. ${ }^{\circ}$ 9.394, entretanto, nos discursos do MEC o Estado, contraditoriamente, é entendido como provedor da educação.

Menciono que a natureza reguladora do Estado foi revelada antes mesmo da homologação da LDB/1996. O Executivo Federal negou qualquer possibilidade de criação de um Fórum Nacional para colaborar na formulação de políticas nacionais da educação. Trata-se da lei n. ${ }^{\circ}$ 9.131, de 24/11/1995, que alterou dispositivos da lei . $^{\circ} 4.024 / 1961$ ao prescrever em seu art. $6^{\circ}$ e respectivo parágrafo $1^{\mathrm{o}}$ :

O Ministério da Educação e do Desporto exerce as atribuições do poder público federal em matéria de educação, cabendo-lhe formular e avaliar a política nacional de educação, zelar pela qualidade do ensino e velar pelo cumprimento das leis que o regem (grifos nossos).

No desempenho de suas funções, o Ministério da Educação e do Desporto contará com a colaboração do Conselho de Educação e das Câmaras que o compõem (Brasil, 1995).

Com a mesma forma de encaminhamento dada pelo Estado regulador e avaliador foram decretados antes da LDB os "procedimentos para o processo de avaliação dos cursos e instituições de ensino superior" que constam do decreto n. ${ }^{\circ} 2.026$, de 10/10/1996 (revogado pelo decreto n. ${ }^{\circ}$ 3.860/2001). Esses procedimentos, segundo o art. $1^{\circ}$ e seus incisos I a IV, compreendiam a análise dos principais indicadores de desempenho global do sistema nacional de ensino superior; a avaliação de desempenho individual das instituições do ensino superior; a avaliação do ensino de graduação por curso abrangendo também a análise dos resultados do Exame Nacional de Cursos (ENC, vulgo 'Provão') e a avaliação dos programas de mestrado e doutorado, por área de conhecimento.

Dando prosseguimento à linha interpretativa com a qual venho elaborando a síntese dos desdobramentos da LDB/1996 e que provocaram mudanças nessa LDB, dou realce à lei n. ${ }^{\circ} 10.861$, de 14/04/2004, à lei n. ${ }^{\circ} 11.096$, de 13/1/2005, ao decreto n. ${ }^{\circ} 5.773$, de 09/05/2006, ao decreto n. ${ }^{\circ} 5.800$, de $8 / 6 / 2006$, aos decretos n. ${ }^{\circ} 6.095$ e n. ${ }^{\circ} 6.096$, ambos de 24/4/2007, ao decreto n. ${ }^{\circ} 6.755$, de 29/1/ 2009 e à lei n. ${ }^{\circ} 12.014$, de 6/8/2009. 
A primeira, nos termos de seu art. $9^{\circ}$, incisos VI, VIII e IX da LDB instituiu o Sinais. Seu art. $5^{\circ}$ estabeleceu o Exame Nacional de Desempenho dos Estudantes (Enade) como componente obrigatório curricular e estabeleceu a responsabilidade do dirigente das instituições no parágrafo $6^{\circ}$ do referido artigo, de efetivar “a inscrição junto ao Instituto Nacional de Estudos e Pesquisas Educacionais". A segunda instituiu o Programa Universidade para Todos (Prouni), objetivando a recuperação histórica do combate ao perverso distanciamento entre as classes sociais do Brasil e a disputa de vagas entre estudantes na universidade brasileira, todavia, ao mesmo tempo estimulou largamente o setor privado com concessão de bolsas em instituições particulares com e sem fins lucrativos.

O decreto n. ${ }^{\circ} 5.773$ foi remetido pelo legislador aos termos da LDB/1996 e dispôs sobre a regulação, supervisão e avaliação de instituições de educação superior e cursos superiores de graduação e sequenciais do sistema federal de ensino. Enfim, essas leis que preconizam o sistema de avaliação do ensino superior são 'fatias' da reforma deste ensino. A reforma universitária tão esperada pela comunidade acadêmica não se concretizou em sua totalidade, em decorrência da demonstração de poder do Estado de 'dividir para governar', o que levou à implementação da reforma em partes desconexas.

Outra 'fatia' da reforma universitária foi expressa no decreto n. ${ }^{\circ}$ 5.800/2006 que instituiu o sistema Universidade Aberta do Brasil (UAB), voltado para o desenvolvimento da modalidade de educação a distância, com a finalidade de expandir e interiorizar a oferta de cursos e programas de educação superior no país. Interferiu diretamente no modelo de formação de professores em virtude de que entre seus objetivos (cf. art. $1^{\circ}$, parágrafo único, incisos I e II) estão oferta prioritária de cursos de licenciatura e de formação inicial e continuada de professores da educação básica e cursos superiores para capacitação de dirigentes, gestores e trabalhadores em educação básica do território nacional. A questão da formação inicial de professores é polêmica, visto que o mundo vivido defende a formação inicial em cursos presenciais, com até $20 \%$ de ensino a distância.

Sobre esse aspecto Luciana Genro (2004) advertiu que as propostas 'picotadas' acerca da reforma universitária contradiziam o compromisso assumido pelo governo Lula com a sociedade, que ficou só na promessa - uma reforma educacional democrática. “Este governo é o velho travestido de novo" (Genro, 2004).

Uma reforma picotada em pedaços desconexos configura-se, então, como a negação da reforma da universidade brasileira, cujo anteprojeto ficou 'engavetado' desde junho de 2004 no Congresso Nacional... Mais uma artimanha do Poder Legislativo com anuência do Executivo. Somente em 2006 surge o PL 7.200 que estabeleceu normas para o ensino superior federal. Outra 'fatia' da reforma universitária que mereceu o seguinte anúncio do jornal O Estado de S.Paulo, em reportagem divulgada no clipping educacional de 09/06/2007: 
“Depois de três anos de debates, projeto não é mais prioridade. Reforma era um dos principais planos do primeiro mandato de Lula. [...] Hoje, não há nem mesmo na Câmara onde discutir o projeto enviado pelo governo."

Na sequência um pacote de 'picotes', trata-se dos decretos n. ${ }^{\circ} 6.095 / 2007$ e n. ${ }^{\circ}$ 6.096/2007. O primeiro estabeleceu diretrizes para o processo de integração das instituições federais tecnológicas para fins de constituição dos Institutos Federais de Educação, Ciência e Tecnologia (Ifets) e o segundo instituiu o Programa de Apoio aos Planos de Reestruturação e Expansão das Universidades Federais (Reuni). Recursos financeiros para os pacotes-picotes não faltam, desde que as instituições se adequem aos desejos e aspirações do Poder Executivo federal com efusivo apoio do Congresso Nacional.

Tais dispositivos que alimentam expansão de vagas públicas, embora necessária, são acolhidos pelo mundo vivido com alguma restrição, considerando que os Ifets têm reconhecida competência para formar técnicos, mas poderão vir a retirar da universidade a prerrogativa de formar professores para ministrarem cursos com qualidade comprometida, pois os quadros docentes dos Ifets, em geral, carecem aperfeiçoamento em cursos de mestrado e doutorado em educação, compatíveis com a complexa tarefa de formar licenciados.

Já o Reuni proporciona um louvável acesso dos trabalhadores à universidade pública, em particular pela oferta de cursos noturnos, período em que poucos cursos 'nobres' são oferecidos. Os ingressos correm risco ao serem tratados mais como trabalhadores do que estudantes universitários, recebendo uma formação menos qualificada do que, por exemplo, os estudantes que têm o privilégio de frequentar cursos de período diurno integral.

No que tange ao decreto n. ${ }^{\circ} 6.755 / 2009$, que instituiu a Política Nacional de Formação de Profissionais do Magistério da Educação Básica e atribui à Coordenação de Aperfeiçoamento de Pessoal de Nível Superior (Capes) da Educação Básica o dever de fomentar programas de formação inicial e continuada, teço a consideração seguinte.

Como desdobramento desse decreto, foi lançado o Plano Nacional de Formação para o Magistério da Educação Básica e o Planejamento Estratégico da Formação Inicial de Professores da Educação Básica Pública, que instiga o fortalecimento do regime de colaboração entre os entes federados. Apesar de que o Planejamento Estratégico esteja jurisdicionado à Diretoria de Ensino Presencial (DEB/Capes), sua execução estimula boa parte de capacitação inicial a distância, por imposição da alta demanda localizada em regiões distantes dos centros mais desenvolvidos. O mundo vivido permanece apreensivo com tais políticas de formação a distância, visto que se posiciona contrário ao ensino a distância aplicado à formação inicial.

Os dispositivos supramencionados demonstram a correlação de forças do mundo oficial em definir políticas educacionais. Esclareço que não me coloco contra a definição de políticas educacionais pelo Estado, pois constitui 
um de seus mais legítimos deveres. Sendo assim, deve o Estado defini-las, bem como destinar recursos financeiros para implementá-las. Manifesto-me, sim, contra o descarte da participação de atores da sociedade civil engajados em movimentos de educadores neste processo, considerando que esse impedimento afronta princípios constitucionais do regime republicano e democrático, do atual governo popular, referendado pelas urnas.

Cabe mencionar ainda a lei que não alterou conteúdos da LDB, mas teve interferência direta e positiva no ensino fundamental. É a lei n. ${ }^{\circ}$ 9.424, de 24/12/1996, que instituiu o Fundef em atendimento ao previsto no Título VII da LDB/1996 que trata do financiamento da educação. Este fundo advém da emenda constitucional n. ${ }^{\circ}$ 14/1996 e da lei que o criou, motivadora de 11 decretos presidenciais e 18 portarias de ministros da Educação. Esses diplomas legais culminaram no decreto de 21/10/2003 que instituiu o grupo de trabalho interministerial para promover estudos concernentes ao Fundeb e portaria do MEC que criou o grupo de trabalho interno com o mesmo objetivo.

Por certo, os movimentos sociais de educadores conseguiram alguma atenção do mundo oficial aos estudos e às severas críticas deflagradas pela academia à não extensão dos recursos do Fundef à educação infantil, ao ensino médio e à educação de jovens e adultos (EJA) que, de acordo com a LDB/1996, a exemplo do ensino fundamental, são integrantes da Educação Básica.

A propósito, o Fundeb, que advém da emenda constitucional n. ${ }^{\circ} 53$, de 19/12/2006, e da medida provisória n. ${ }^{\circ} 339$, de 28/12/2006, convertida na lei n. ${ }^{\circ} 11.494$, de 20/06/2007, objetiva corrigir distorções de destinação de recursos financeiros provocadas pelo Fundef. Neste momento são inúmeras as expectativas em relação ao Fundeb, mas a prudência indica que somente uma avaliação futura poderá oferecer melhores indicadores de sua aplicação. É preciso, todavia, reconhecer como ponto positivo a intencionalidade do financiamento da educação infantil, da EJA e do Ensino Médio. Também mostram relevância as exigências de que, para receber os respectivos percentuais desses fundos, os estados e municípios devem ter elaborado e em desenvolvimento, entre outros, planos de carreira do magistério, bem como implantados conselhos fiscalizadores da aplicação desses recursos.

Ainda que tenha havido e permaneçam desvios e descumprimento das exigências que condicionaram e condicionam o recebimento de recursos do Fundef e Fundeb em alguns estados e municípios, identifico impactos positivos destes fundos. Por um lado, interferiram na profissão do professor com a garantia de uma carreira para valorizar o magistério atribuindo salários dignos, formação continuada feita com licença remunerada e alguma melhoria nas condições de trabalho e, por outro, estimularam a participação da comunidade em conselhos como exercício de uma gestão democrática fiscalizadora do emprego adequado dos recursos na escola básica. 
Neste contexto, é justo lembrar que as conquistas apontadas no parágrafo anterior foram reivindicações de associações e sindicatos da categoria profissional, representantes do mundo vivido. Entre eles merecem destaque a Confederação Nacional dos Trabalhadores da Educação (CNTE) e o Sindicato Nacional dos Docentes das Instituições de Ensino Superior (Andes).

Decorrente também de intensa luta pela valorização dos profissionais da educação, em especial, das associações acadêmicas nominadas na nota três e dos sindicatos, foi homologada a lei n. ${ }^{\circ} 11.738$, de 16/7/2008, que instituiu o piso salarial profissional nacional dos profissionais do magistério, no valor de $\mathrm{R} \$ 950,00$ (novecentos e cinquenta reais), para o professor formado na modalidade Normal do Ensino Médio, com 40h semanais. Essa é também mudança decorrente da LDB/1996 (cf. art.67, inciso III), embora não altere seus conteúdos, visto que atende o que preconiza a Constituição Federal. Contrariado com a matéria, o mundo oficial representado pelo Executivo do RS, SC, PR, MS e CE, com o apoio de SP, MG, TO, RR e DF, moveram Ação Direta de Inconstitucionalidade contra a Lei do Piso. Sabiamente o Judiciário julgou improcedente a solicitação dos governadores, mas reflexos negativos foram sentidos pelos educadores: o prazo de vigência do piso de 1/1/2008 foi alterado para 1/1/2009... Artimanhas do Executivo.

Acrescento, ainda, a este conjunto de diplomas legais mais alguns que, apesar de não provocarem mudanças explícitas no que estabelece a LDB, são dispositivos necessários à prática da educação inclusiva, um dos princípios da educação nacional contidos na lei. Desse modo, tornaram-se realidade as reivindicações de movimentos que defendem direitos dos portadores de necessidades especiais. Tais diplomas legais são os seguintes: a) lei n. ${ }^{0} 10.098 / 2000$, que estabeleceu normas sobre condições materiais e de comunicação para acessibilidade dos alunos, a fim de transitarem pelos espaços e participar das atividades escolares; b) lei n. ${ }^{\circ}$ 10.436/2002, que dispõe sobre o uso da língua brasileira de sinais (Libras) e formação de professores nesta especialidade como pré-requisito para atendimento do deficiente auditivo.

Sob a égide dos princípios da educação inclusiva também foram sancionados a lei n. ${ }^{\circ} 11.096$, de 13/01/2005, e o decreto n. ${ }^{\circ}$ 5.493, de 18/07/2005, que, como os diplomas legais antes analisados, não alteram dispositivos da LDB/1996, mas regulamentaram o Programa Universidade para Todos (Prouni), tornando lícito o acesso ao ensino superior de estudantes de baixa renda procedentes da escola média pública. Ademais, tais diplomas introduzem um procedimento de cooperação do Poder Público com as instituições privadas de ensino superior com fim e sem fim lucrativo não previsto na LDB, no que diz respeito à socialização democrática do conhecimento acumulado pela humanidade e que historicamente tem sido privilégio da classe dominante. 
Retomando o compromisso antes firmado de apresentar algumas mudanças na LDB, a meu ver, mais consentâneas com a natureza deste artigo, passo a registrá-las de modo bastante sucinto.

A primeira modificação decorreu da lei n. ${ }^{\circ} 9.475 / 1977$, portanto sete meses depois de homologada a LDB. Essa nova lei incide sobre o ensino religioso, disposto no art. 33 e seus parágrafos. Do caput desse artigo é retirada a expressão 'sem ônus para os cofres públicos' e inserida outra 'é parte integrante da formação básica do cidadão'. São também alterados parágrafos do art. 33, sendo atribuída responsabilidade aos sistemas de ensino para definir conteúdos do ensino religioso, após oitivas com as diferentes confissões religiosas, e o estabelecimento das normas para habilitação e admissão dos professores da rede pública, agora legalmente remunerados com recursos públicos.

Diante dessa mudança, uma vitória se materializa. Então, indago: Vitória de quem?

Desafortunadamente, saíram vitoriosos os defensores do ensino religioso, alinhados aos princípios que regem a escola privada e que estavam inconformados com a expressão 'sem ônus para os cofres públicos', inserida no texto original da LDB como reivindicação do Fórum, com base na justificativa de que recursos públicos devem ser destinados exclusivamente à educação pública.

Outra lei foi sancionada com a finalidade de cumprir a determinação contida na LDB/1996, no parágrafo único do art. 49. A lei n. ${ }^{\circ}$ 9.536/1997 é entendida aqui como desdobramento da LDB, considerando que regulamentou as transferências ex officio, direito de estudantes cujas situações especiais são garantidas pelas prescrições deste dispositivo legal.

Como desdobramento também da LDB para atender aos termos do art. $9^{\circ}$, inciso I, foi elaborado o Plano Nacional de Educação, aprovado pela lei n. ${ }^{\circ}$ 10.172/2001, que de fato pretendeu dar certa organicidade ao sistema nacional de educação, à medida que apresenta diagnóstico de cada nível e modalidade de ensino, propõe metas e objetivos na esfera da União e atribui aos estados e municípios a obrigatoriedade da elaboração de planos estaduais e municipais. Lamentavelmente, o PNE/2001 foi condenado a não atender ao previsto em seus dispositivos porque recebeu nove vetos da Presidência da República, todos concernentes aos dispositivos que prenunciavam uma possível ampliação de verbas da União a serem investidas na educação nacional. Neste episódio cabe denúncia da presença ostensiva do mundo oficial contra os interesses do mundo vivido dos professores e da escola pública.

Nova mudança é ocasionada pela lei n. ${ }^{\circ} 10.639 / 2003$ que acrescentou dois artigos na LDB (26-A e 79-B), tornando obrigatório no ensino fundamental e médio, da rede pública e privada, o ensino da história e da cultura afro-brasileira. Essa lei também instituiu o dia nacional da consciência negra. A meu ver, tal lei evidencia uma conquista da luta do movimento étnico de 
afro-descendentes e se configura em resgate na história brasileira da cultura de um povo que contribuiu largamente para o desenvolvimento da nação.

No que concerne ainda ao ensino fundamental, houve outras alterações da LDB decorrentes da lei $n .{ }^{\circ} 11.114 / 2005$, que alterou os art. $6^{\circ}$ e 32 , para tornar obrigatória a matrícula das crianças de seis anos de idade no ensino fundamental, e da lei n. ${ }^{\circ} 11.274 / 2006$, que estendeu para nove anos a duração desse nível de ensino, com início aos seis anos de idade e alterou artigos que tratam do recenseamento dos educandos desse nível.

Entendo serem essas alterações uma conquista também dos movimentos de educadores que conseguiram tocar a sensibilidade dos legisladores para o significado do ensino fundamental público e gratuito com nove anos de duração, visto que um percentual elevado de crianças e jovens pertencentes à classe social desfavorecida tem uma única oportunidade de escolarização: a escola pública e gratuita.

Mais uma lei incidiu em mudança na LDB/1996, em seu art. 61, a lei n. ${ }^{\circ}$ 12.014. Tem por finalidade discriminar as categorias de trabalhadores considerados profissionais da educação escolar básica. São eles: professores habilitados em nível médio ou superior para a docência na educação infantil e nos ensinos fundamental e médio; trabalhadores em educação portadores de diploma de pedagogia, com habilitação em administração, planejamento, supervisão, inspeção e orientação educacional, bem como com títulos de mestrado ou doutorado nas mesmas áreas; trabalhadores em educação, portadores de diploma de curso técnico ou superior em área pedagógica ou afim. Essa lei, por um lado, dispõe acertadamente sobre a inclusão de todos que exercem funções na educação escolar na categoria 'profissionais da educação'. Por outro, anacronicamente recupera a divisão social do trabalho docente sob uma visão tecnicista e fragmentária ao reconhecer os 'especialistas' formados mediante habilitações no curso de Pedagogia. Na realidade, a formação de 'especialistas' foi extinta nas faculdades e centros de educação públicos, como foram extintas, pela resolução CNE/CP n. ${ }^{\circ} 1$, de 15/05/2006, as habilitações que concediam título de 'especialista' ao pedagogo.

De modo intencional deixei os momentos finais deste artigo para mencionar alguns desdobramentos da LDB que atingiram o campo de formação de profissionais da educação de modo altamente negativo e que expressam cruelmente a contradição entre o mundo vivido e o mundo oficial e as conflitantes e divergentes projetos e concepções de sociedade, de cidadania, de educação, de escola, de ensino e de formação de professores para a escola básica.

Em primeiro lugar, desejo recuperar o que já escrevi em trabalho anterior que o cenário de mais de uma década de LDB/1996 continua emoldurado pelas ações do mundo do sistema em contraposição ao mundo vivido dos educadores brasileiros, e que a lei vem ainda suscitando diversas interpretações consoante princípios, ideologias e ideários pedagógicos de quem a examina. 
Em segundo lugar, quero me referir à instalação desordenada dos Institutos Superiores de Educação (ISEs) que abrigam em seu interior escolas normais superiores, com finalidade de formar professores para a educação infantil e ensino fundamental de $1^{\circ}$ ao $5^{\circ}$ ano. Aproveitando-se da abertura contida nos art $1^{\circ}$ e art $4^{\circ}$ da resolução CNE/CP n. ${ }^{\circ} 1$, de 30/09/1999, um desdobramento da LDB, o ISE desobrigou-se de realizar pesquisa, como se fosse possível formar professores aulistas que repetem acriticamente conteúdos, em atividade denominada ensino, com uma prática pedagógica que se sustenta no simples saber fazer, para resolver problemas do cotidiano escolar. Mais uma vez, as políticas educacionais pouco se detiveram à qualidade na formação de professores.

Da mesma forma, a força do decreto n. ${ }^{\circ} 3.276$, de 06/12/1999, golpeou o mundo vivido dos educadores impondo a formação de professores da educação infantil e do ensino fundamental dos anos iniciais exclusivamente nos ISEs. Diante de sucessivas investidas do mundo vivido contra o mundo oficial, no ano seguinte, houve uma modificação do decreto supra: o novo dispositivo, entretanto, não produziu justiça, deixando de atribuir à universidade a formação de professores, como lócus mais expressivo da articulação entre a pesquisa e o ensino.

Em terceiro lugar, preciso assinalar que deliberadamente o mundo oficial facilitou a certificação de professores em cursos de licenciatura de qualidade duvidosa quando permitiu a proliferação de cursos a distância para formar professores, enquanto que em outras áreas de conhecimento essa modalidade tem natureza proibitiva e vigiada por organismos da sociedade civil que regulam as profissões, por exemplo, conselhos e ordem de profissionais.

Em quarto lugar é preciso admitir que a partir de 1997 o Conselho Nacional de Educação (CNE) iniciou o processo de reforma das diretrizes curriculares das várias áreas do conhecimento. As críticas aos currículos vigentes no período apontavam que esses eram muito rígidos, resultante da fixação dos mínimos curriculares; que o tempo de conclusão era longo demais; e que não vislumbrava a formação inicial como uma etapa do processo de formação. Para encaminhar as necessárias ações, o Ministério da Educação (MEC) constituiu comissões de especialistas para que pudessem, junto a sua comunidade acadêmica, discutir a questão.

Tal processo, inicialmente bastante promissor, teve um desfecho surpreendente sobretudo no tocante às Diretrizes Curriculares Nacionais do Curso de Pedagogia, que foram encaminhadas ao CNE pela Secretaria de Ensino Superior, em 1999, e foi sendo postergada sua homologação no âmbito deste Conselho, porque não correspondiam aos interesses do mundo oficial (leiase aqui $\mathrm{CNE}$ ), naquela ocasião, com maioria de conselheiros atrelados ao sistema privado de ensino. 
Finalmente essas diretrizes foram elaboradas pelo CNE e homologadas pelo ministro da Educação em 2006 pela resolução $\mathrm{CNE} / \mathrm{CP}$ n. ${ }^{\circ}$ 01, de 15/05, sendo a última área de formação de professores que teve suas diretrizes aprovadas. Se, por um lado, ser a última evidencia resistência dos educadores às investidas do mundo oficial, por outro, revela alguma conquista do movimento de educadores ao elegerem a docência como base da formação de todos os profissionais da educação, reconhecendo assim as diretrizes curriculares a existência obrigatória de uma base comum nacional, a meu ver, conferindo identidade a esses profissionais.

A trajetória da LDB/1996 e os desdobramentos pós-LDB trazidos aqui, ainda que de modo sucinto, pretendiam demonstrar aquilo que ensejava Gramsci (em epígrafe), no início do século XX: sou vivo, sou militante, por isso tomo partido e luto pelos interesses da maioria da população. É lamentável que essa maioria, em nosso país, continue no século XXI desprovida da educação pública, gratuita e de qualidade socialmente referenciada, em todos os níveis e modalidades de ensino, como direito fundamental de garantia de cidadania em uma república que se autodenomina democrática.

Ao longo do transcurso de mais de uma década da LDB/1996, assevero com a autoridade de quem milita no movimento de educadores que não foram abrandadas as contradições e as disputas entre o ensino público e o ensino privado em nosso país.

Afirmo com segurança também que houve desenvolvimento do campo educacional na Década da Educação por tudo que foi possível produzir, segundo a rigorosidade do paradigma para produzir ciência, assim como esse processo suscitou a práxis como patamar elevado da prática dos educadores.

\section{Notas}

1 Professora titular da Universidade Católica de Goiás (UCG). Professora aposentada da Universidade de Brasília (UnB). Coordenadora do Programa de Pós-graduação em Educação da (UCG). Doutora em Administração Educacional pela Universidade de São Paulo (USP). <iria@ucg.br>

Correspondência: Rua Dom Orione, n. ${ }^{\circ}$ 188, apto.101, Edifício Lagoa dos Mares, Setor Oeste, CEP 74140-080, Goiânia, Goiás, Brasil.

2 Tempo suficiente para que a lei aprovada já nascesse anacrônica.

3 Conforme anteprojeto na íntegra, no Anexo II, em Brzezinski (2007). 
4 Por ter maior conhecimento das atividades das associações científicas pelo fato de delas participar sistematicamente, destaco no movimento de educadores, como exemplo, as ações conjuntas da Anfope (Associação Nacional pela Formação dos Profissionais da Educação), Anped (Associação Nacional de Pós-Graduação e Pesquisa em Educação), Anpae (Associação Nacional de Políticas e Administração da Educação), Cedes (Centro de Estudos Educação \& Sociedade) e Forundir (Fórum de Diretores de Faculdades de Educação das Universidades Públicas).

\section{Referências}

BRASIL. Lei n. ${ }^{\circ}$ 9.131, de 24/12/1995. Altera dispositivos da lei n. ${ }^{\circ} 4.024$, de 20 de dezembro de 1961, e dá outras providências. Disponível em: <www.planalto.gov.br>. Acesso em 15 set. 2009.

. Decreto n. ${ }^{\circ} 2.026$, de 10/10/1996 Estabelece procedimentos para o processo de avaliação dos cursos e instituições de ensino superior. Disponível em: <www.planalto. gov.br>. Acesso em: 15 set. 2009.

Emenda constitucional n.$^{\circ} 14$, de 12/09/1996. Modifica os arts. 34, 208, $211 \mathrm{e}$ 212 da Constituição Federal e dá nova redação ao art. 60 do Ato das Disposições Constitucionais Transitórias. Brasília: DOU, de 13/09/1996, Seção 1, p. 18.109.

Lei n. ${ }^{\circ}$ 9.394, de 20/12/1996. Estabelece a lei de diretrizes e bases da educação nacional. In: BRZEZINSKI, Iria. LDB interpretada: diversos olhares se entrecruzam. 10. ed. São Paulo: Cortez, 2005. p. 246-266.

Lei n. ${ }^{\circ}$ 9.424, de 24/12/1996. Dispõe sobre o Fundo de Manutenção e Desenvolvimento do Ensino Fundamental e de Valorização do Magistério. Brasília: DOU, de 26/12/1996, Seção 1, p. 28.443.

Decreto n. ${ }^{\circ}$ 3.276, de 06/12/1999. Dispõe sobre a formação em nível supe- rior de professores para atuar na educação básica. Brasília: Gráfica do Senado, DOU, de 07/12/1999.

Decreto n. ${ }^{\circ} 3.554$, de 07/08/2000. Dá nova redação ao $\S 2^{\circ}$ do art. $3^{\circ}$ do decreto n. ${ }^{\circ} 3.276$, de 06/12/1999. Brasília: Gráfica do Senado, DOU, de 07/08/2000.

Lei n. ${ }^{\circ}$ 10.172, de 09/01/2001. Aprova o Plano Nacional de Educação e dá outras providências. Disponível em: <www. planalto.gov.br>. Acesso em: 18 set. 2009.

Lei n. ${ }^{\circ} 11.096$, de 13/01/2005. Institui o Programa Universidade para Todos (Prouni) e dá outras providências. Disponível em: <www.planalto.gov.br>. Acesso em: 18 set. 2009.

Decreto n. ${ }^{\circ}$ 5.773, de 09/05/2006. Dispõe sobre a regulação, supervisão e avaliação de instituições de educação superior e cursos superiores de graduação e sequenciais do sistema federal de ensino. Disponível em: <www.planalto.gov.br >. Acesso em: 18 set. 2009.

MEC.CNE. Resolução CNE/CP n. ${ }^{\circ} 1$ de 15/05/2006. Institui diretrizes curriculares nacionais para o curso de graduação em Pedagogia, licenciatura. Brasília: DOU, de 16/5/2006, Seção 1, p. 11. 
Decreto n. ${ }^{\circ} 5.493$, de 18/07/2005. Regulamenta o disposto na lei . $^{\circ} 11.096$, de 13/01/2005. Disponível em: <www.planalto. gov.br>. Acesso em: 18 set. 2009.

Decreto n. ${ }^{\circ} 5.800$, de 8/6/2006. Instituiu o Sistema Universidade Aberta do Brasil (UAB). Disponível em: <www.planalto. gov.br>. Acesso em: 18 set. 2009.

Emenda constitucional n. ${ }^{\circ}$ 53, de 19/12/2006. Dá nova redação aos arts. $7^{\circ}, 23$, 30, 206, 211 e 212 da Constituição Federal e dá nova redação ao art. 60 do Ato das Disposições Constitucionais Transitórias. Disponível em: <www.planalto.gov.br>. Acesso em: 30 set. 2009.

- Medida provisória n. ${ }^{\circ}$ 339, de 28/12/2006. Regulamenta o art. 60 do Ato das Disposições Constitucionais Transitórias. Disponível em: <www.planalto.gov.br>. Acesso em: 30 set. 2009.

Decreto n. ${ }^{\circ}$ 6.095, de 24/04/2007. Estabelece diretrizes para o processo de integração de instituições federais de educação tecnológica, para fins de constituição dos Institutos Federais de Educação, Ciência e Tecnologia (Ifet), no âmbito da Rede Federal de Educação Tecnológica. Disponível em: <www.planalto.gov.br>. Acesso em: 30 set. 2009 .

Decreto n. ${ }^{\circ}$ 6.096, de 24/04/2007. Institui o Programa de Apoio a Planos de Reestruturação e Expansão das Universidades Federais (Reuni). Disponível em: <www. planalto.gov.br>. Acesso em: 30 set. 2009.

Lei n. ${ }^{\circ} 11.494$, de 20/06/2007. Dispõe sobre o Fundo de Manutenção e Desenvolvimento do Ensino fundamental e de Valorização do Magistério. Disponível em: <www. planalto.gov.br>. Acesso em: 30 set. 2009.

Decreto n. ${ }^{\circ} 6.755$, de 29/1/2009. Institui a Política Nacional de Formação de Profissionais do Magistério da Educação Básica, disciplina a atuação da Coordenação de Aperfeiçoamento de Pessoal de Nível Superior (Capes) no fomento a programas de formação inicial e continuada. Disponível em: <www. planalto.gov.br>. Acesso em: 12 fev. 2009.

Lei n. ${ }^{\circ} 12.014$, de 6/8/2009. Altera o art. 61 da lei n. ${ }^{\circ} 9.394$, de 20 de dezembro de 1996, com a finalidade de discriminar as categorias de trabalhadores que se devem considerar profissionais da educação. Disponível em: <www.planalto.gov.br>. Acesso em: 28 ago. 2009.

BRZEZINSKI, Iria (org). LDB interpretada: diversos olhares se entrecruzam. 10. ed. São Paulo: Cortez, 2007.

(org). $L D B$ dez anos depois: reinterpretada sob diversos olhares. 2. ed. São Paulo: Cortez, 2008.

CURY, Carlos R. J. Ideologia e educação brasileira: católicos e liberais. 2. ed. São Paulo: Cortez; Autores Associados, 1984.

DIDONET, Vital. LDB dez anos depois: uma retrospectiva da ação legislativa. In: BRZEZINSKI, Iria (org). LDB dez anos depois: reinterpretada sob diversos olhares. 2 ed. São Paulo: Cortez, 2008. p. 42-61.

ESTADO DE S.PAULO. Reforma universitária está parada na Câmara há 1 ano. Disponível em: $<$ www.editau.com.br/clippingeducaciona $>$. Acesso em: 9 jun. 2007.

FERNANDES, Florestan. Diretrizes e bases: conciliação aberta. Educação e Sociedade, Campinas, a. XI, n. 36, p. 142-147, ago. 1990.

GENRO, Luciana. Ato em defesa da universidade pública denuncia autoritarismo do governo. Disponível em: <www.andes.org.br/ Clipping >. Acesso em: 15 maio 2009.

GRAMSCI, Antonio. Indifferenti. Jornal Cittá Futura, Turim, único número, 11 fev.1917. Tradução livre de Roberto Della Santa Barros. Revista Espaço Acadêmico, a. VI, n. 64, set. 2006. Disponível em: <www.espacoacademico. com.br>. Acesso em: 28 maio 2009.

Os intelectuais e a organização da cultura. 3. ed. Tradução de Carlos Nelson 
Coutinho. Rio de Janeiro: Civilização Brasileira, 1979.

PINO, Ivany. A Lei de Diretrizes e Bases da Educação: ruptura do espaço social e a organização da educação nacional. In: BRZEZINSKI, Iria (org). LDB interpretada: diversos olhares se entrecruzam. 10. ed. São Paulo: Cortez, 2007. p. 19-42.

SAVIANI, Dermeval. A nova lei da educação: trajetória, limites e perspectivas. Campinas: Autores Associados, 1997.
. Da nova $L D B$ ao Fundeb: por uma outra política educacional. Campinas: Autores Associados, 2007.

VEYNE, Paul. Como se escreve a história: Foucault revoluciona a história. Brasília: UnB, 1982.

Recebido em 02/06/2009

Aprovado em 01/07/2010 